\title{
Biomimetics - A Potential Solution to Drag Reduction in Modern Aerodynamics
}

\author{
D Bhatia ${ }^{1 *}$ and J Wang ${ }^{2}$ \\ ${ }^{1}$ School of Aerospace Engineering, The University of Nottingham Ningbo China, Ningbo, China \\ ${ }^{2}$ Faculty of Science, Engineering and Computing, Kingston University London, London, United Kingdom
}

*Corresponding author: Dinesh Bhatia, School of Aerospace Engineering, The University of Nottingham Ningbo China, Ningbo, China.

Received Date: October 22, 2019

Published Date: October 29, 2019

\section{Introduction}

By the year 2050, global aviation emissions are expected to grow by $300-500 \%$ as compared to 2005 [1]. With climate change becoming a reality, there is increasing environmental, political, and economic pressure to improve fuel efficiency and reduce carbon emissions associated with transportation. The European Commission has set an ambitious target of reducing aviation emissions by $75 \%$ by 2050 [2].

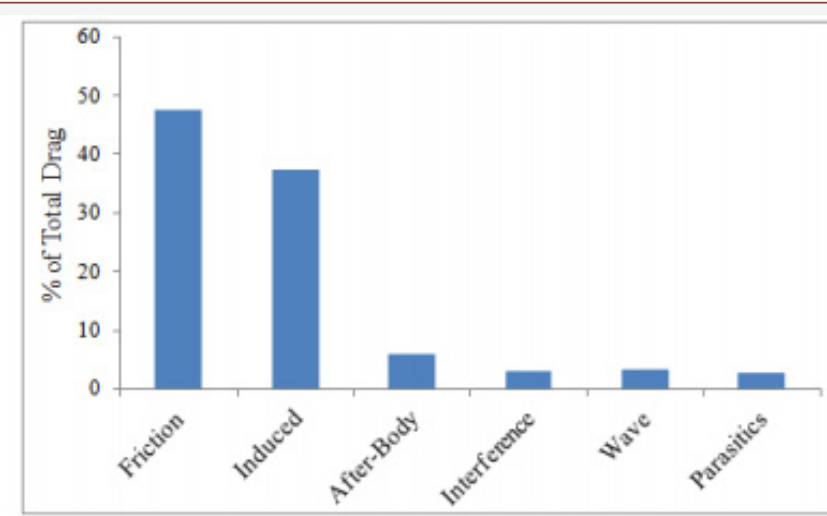

Figure 1: Total drag breakdown fora commercial aircraft from Gowree [6].

Reduction in aircraft emissions can be brought either through improvements in propulsion technology or reduction in drag generated by the aircraft. In terms of propulsion technology, current trends tend to be geared towards electrification of the propulsion system as observed in the More Electric Aircraft (MEA) initiative [3]. However, commercial electric aviation is in its nascency and a mature technology, by conservative estimates, is 20-40 years away from fruition [4]. In the present scenario, drag reduction is one of the most promising methods to try and achieve this goal. It is estimated that even a $10 \%$ reduction in drag (through skin friction reduction) can lead to fuel savings of $\$ 200$ million/year for the aviation sector [5]. Skin friction constitutes about half of all

drag generated by the aircraft as shown in Figure 1 [6]. Reduction of friction drag would greatly contribute towards the reduction in emissions from aircraft. However, conventional drag reduction methods have either plateaued or possess great difficulty in their practical implementation-details of which can be found based on an extensive study by Jahanmiri [7].

The reduction in skin friction drag can be attained by looking at possible solutions from nature i.e. Biomimetics. Biomimetics, by definition, is the approach to human innovation by emulating nature. One only has to look at the relative ease at which sharks swim at high speed (75 kph), even though, they possess such a large mass (545 kg) to realize the low drag that they produce [8]. The low drag phenomenon of sharks can be explained by observing the shark skin. The shark skin (and those of other elasmobranch fishes such as skates, rays, etc.) are covered by minute placoid scales known as dermal denticles [9]. Sharks also possess very fine longitudinal ridges called riblets [9]. The dermal denticles and the riblets are also supplemented by a mucous layer which not only enable sharks to swim with minimum drag and catch prey but also promote anti-fouling behaviour [10-11].

Shark-skin inspired studies have been conducted extensively in the field of hydrodynamics with great efficacy. Biomimetic incorporation of the riblet based geometries has been the inspiration for drag reduction in the world of hydrodynamics since the last 30 years. Dean and Bhushan have presented a comprehensive review of riblet based drag reduction mechanisms in a hydrodynamic environment [12]. Biomimicry of these shark skin riblet based geometries became so popular that they were used in commercial applications such as the Speedo FSII swimsuit which demonstrated a drag reduction of $7.7 \%$ under live swimming conditions and $10-15 \%$ reduction under stiff-body conditions as 
compared to conventional swimsuits [13]. Thus, the shark-skin inspired riblets have shown great promise when used in water.

The authors believe that the biomimicry of the shark skin can also be translated to the field of aerodynamics. The authors base their opinion not only on existing data available from the hydrodynamic environment but also based on existing studies that make use of generic riblet shaped geometries to reduce turbulent skin friction drag. In most of these studies, the presence of a riblet shaped geometry either led to a net reduction in skin friction drag or led to a reduction in cross flow motion within the boundary layer and thereby reducing momentum transport away from the boundary layer [14-15].

However, there exist potential hurdles in the development of a riblet based features to enable drag reduction within the laminar boundary layer. Firstly, the positioning of these riblets need to be optimized within the laminar boundary layer (as opposed to the turbulent boundary layer in existing studies). Secondly, the size and shape of these riblets would have to be optimized based on the shark skin. The authors are of the opinion that on the completion of the optimization of these shark skin inspired riblet based geometries, these riblets could be placed strategically on the surface of the aircraft wing to try and reduce drag.

Biomimetics could also find its way into renewable energy applications such as wind turbines. Surface coatings bearing the same consistency as the mucous secreted on the shark skin could be used for anti-icing of wind turbine blades. Ice-accretion could be reduced on the surface owing to the use of the very low friction surface coating. The use of these biomimetic surface coatings could also contribute to self-cleaning wind turbine blades which would reduce debris accumulation and ice accretion on the surface of the turbine blades. A reduction in ice-accretion would reduce the drag on the wind turbine blades thereby improving their efficiency and reducing their downtime.

Thus, biomimetics provides us with a unique way forward to enable drag reduction without the use of complicated solutions. As Ockam's Razor states, "The simplest solution is most likely the right one", biomimetics gives us an opportunity to attain drag reduction using simple and straightforward solutions inspired by verifiable examples observed in nature.

\section{Acknowledgement}

None.

\section{Conflict of Interest}

No conflict of interest.

\section{References}

1. European Comission (2016) European Comission on Reducing Emissions from Aviation. EU Comission Report.

2. European Commission (2011) Flightpath 2050 Europe's Vision for Aviation Report of the High-Level Group on Aviation Research. Luxembourg.

3. (2019) More Electric Aircraft - MEA - Next Generation Aircraft Power.

4. M Hovis (2014) How Far Away Is Commercial Electric Aviation?

5. MJ Walsh, WL Sellers III, CB Mc Ginley (1989) Riblet drag at flight conditions. J Aircr 26(6): 570-575.

6. ER Gowree (2014) Influence of Attachment Line Flow on Form Drag.

7. M Jahanmiri (2011) Aircraft drag reduction: an overview.

8. (2019) Spilling The Secret To A Mako Shark's Speed.

9. AW Lang, P Motta, P Hidalgo, M Westcott (2008) Bristled shark skin: a microgeometry for boundary layer control? Bioinspir Biomim 3(4): 046005.

10. DW Bechert, M Bruse, W Hage, R Meyer (2000) Fluid mechanics of biological surfaces and their technological application. Naturwissenschaften 87(4): 157-171.

11. GD Bixler, B Bhushan (2013) Fluid drag reduction with sharkskin riblet inspired microstructured surfaces. Adv Funct Mater 23(36): 4507-4528.

12. B Dean, B Bhushan (2010) Shark-skin surfaces for fluid-drag reduction in turbulent flow: a review. Philos Trans A Math Phys Eng Sci 368(1929): 4775-4806.

13. J Oeffner, GV Lauder (2012) The hydrodynamic function of shark skin and two biomimetic applications. J Exp Biol 215(5): 785-795.

14. H Choi, P Moin, J Kim (1993) Direct numerical simulation of turbulent flow over riblets. J Fluid Mech 255(1): 503.

15. DW Bechert, M Bartenwerfer (1989) The viscous flow on surfaces with longitudinal ribs. J Fluid Mech 206(1): 105. 